\title{
Uma análise crítica sobre as modificações da área central de Duque de Caxias: a paisagem em disputa
}

\author{
Danilo Porcari \\ Mestrando em Geografia - PUC/Rio \\ danilocloud@hotmail.com
}

\begin{abstract}
Resumo
O artigo busca colocar em perspectiva a paisagem, através de uma breve discussão teórica para, em seguida, auxiliar no entendimento do objeto de estudo do texto, enfatizando as modificações e os conflitos resultantes da disputa pela paisagem do Centro de Duque de Caxias, os quais têm como uma de suas origens a construção de um novo shopping na parte central da cidade. Esta modificação na paisagem aponta para a proeminência do valor de troca em detrimento do valor de uso, e, irá afetar a vida cotidiana de parcela da população. O artigo irá expor algumas contradições do processo tentando assim desmitificar essa paisagem que se constrói. Busca-se, também, colaborar com a luta da sociedade civil que está organizada em uma entidade, o FORAS, que atua na luta contra a construção do shopping.
\end{abstract}

Palavras chave: Paisagem, Duque de Caxias, Conflitos, Bem-estar.

THE DUQUE DE CAXIAS LANDSCAPE AS CAPITAL OF THE ADVANCING FRONT A critical analysis of the changes in the landscape of the central area of Duque de Caxias

\begin{abstract}
The article seeks to do a debate on the landscape, initially a brief theoretical discussion to assist in the understanding of the text of the subject matter, which are the changes and conflicts resulting from the dispute over the landscape and the Duque de Caxias Center generated by construction a new mall that is landscape change that favors the exchange at the expense of use will affect the entire well-being of a good portion of the population. The article will expose
\end{abstract}


some contradictions of the process thus trying to demystify this landscape that is constructed, also seeks to collaborate with the struggle of civil society that is organized into an entity the forces that present in the fight against the construction of the mall.

Keywords: Landscape, Duque de Caxias, Conflict, Wellbeing.

\section{Introdução}

O objetivo deste artigo é fazer uma reflexão acerca dos conflitos que estão acontecendo na cidade de Duque de Caxias cujas origens podem ser vistas em grande medida pelo processo que envolve a construção do shopping Central Park. Enfatizamos o olhar da paisagem, mas não um olhar restrito apenas ao sentido da visão, mas lançando mão de uma perspectiva crítica para analisar a complexidade das relações e suas contradições que não serão tomadas adequadamente se nos detivermos apenas na aparência, forma usual com a qual a paisagem é frequentemente vista.

No primeiro momento, se faz necessário uma breve discussão acerca do conceito de paisagem para ajudar na compreensão do processo que vem ocorrendo em Duque de Caxias. Para isso, buscou-se uma interlocução inicial a partir de leituras de vários autores que discutem a conceito de Paisagem, incluindo-se a pesquisa realizada pelo IPPUR - Instituto de Pesquisa e Planejamento Urbano e Regional - acerca do processo de construção do referido shopping. Acrescentamos nossa própria vivência junto aos movimentos sociais existentes em Duque de Caxias. Nesse sentido, em especial, na discussão que envolve 0 conceito de paisagem, destacou-se como interlocutores: SANTOS (2002), COSGROVE (1998), BESSE (2014), SOUZA (2013), BERQUE (1998), CASTRO (2002), ROSENDAHL (1998), HOLZER (1999), CORRÊA (1999).

A inquietação que levou ao trabalho originou-se a partir de simples e frequentes caminhadas pelo centro de Duque de Caxias, onde foram percebidas novas formas que destoavam do restante da paisagem. Assumimos que não se tem a pretensão de trazer ideias prontas, pois, as múltiplas determinações do movimento do real são inesgotáveis. Nossa pretensão 
também tem como direção contribuir com a luta organizada contra a construção do shopping em tela.

Este artigo, assim, procura analisar a paisagem urbana de Duque de Caxias, destacadamente, a área do entorno da construção do novo shopping e suas relações estabelecidas direta ou indiretamente com o modo de produção capitalista, daí nossa ênfase sobre o conflito que passa a ser visto entre o uso (aqui considerado, como momento de apropriação dos espaços, livre dos constrangimentos que se colocam com as transformações em que o capital se desenvolve e intensifica sua intervenção em relação ao urbano) e a troca (momento em que aqueles constrangimentos se exacerbam). Nesse sentido, necessários se faz ainda analisar os aspectos culturais, econômicos, os aspectos físicos do lugar, a ideologia dominante e a própria ação do Estado que tem certa posição, nem sempre apreendida imediatamente. Todavia, o fato mais notável e que merece atenção mais acurada, é que a todo o tempo o poder instituído, especificamente, o estatal, se apresenta, aparentemente, como neutro e mediador de conflitos. Diante disto, é mister considerar que a formação/construção da paisagem não é neutra, ela é carregada de intencionalidades geradas por uma determinada ideologia pertencente a uma classe dominante, mas que não exclui as tensões representadas pelos movimentos de resistência.

\section{Breve reflexão acerca da paisagem}

Este trabalho busca entender as modificações que estão ocorrendo no processo de construção do shopping Central Park em Duque de Caxias. Para não ficarmos "refém" da paisagem imediata é necessário se fazer uma discussão sobre o conceito de paisagem e qual a importância deste conceito para a compreensão das mediações que se colocam entre o mundo da vida e os espaços ditos concebidos, onde o primeiro passa a ser tomado de forma problematizada com as mediações necessárias, de forma que se possa apontar para suas múltiplas determinações.

O termo paisagem é um dos conceitos-chave da geografia que por muito tempo foi colocado como secundário perdendo importância em relação aos 
conceitos de região, território, lugar e espaço quando a geografia clássica sofre inclusive grande influência do positivismo. A discussão acerca da paisagem está sendo cada vez mais retomada, agora de forma mais complexa abrangendo outras noções como as de representação, imaginário, simbolismo e a percepção, ampliando seus horizontes inclusive de forma interdisciplinar. 0 conceito de paisagem é utilizado em várias ciências, como, por exemplo, na ecologia, na geografia, na história e até nas artes. A ideia de paisagem está diretamente relacionada às questões estéticas, culturais, históricas e espaciais de um determinado grupo social. Vale destacar ainda que essa noção é resultado de um processo espaço-temporal das experiências humanas, carregada de intencionalidades.

A origem do termo paisagem é bem complexa, essa discussão acaba por esbarrar com traduções de diversas línguas como as discussões sobre landscape, paysage, landschaft, outras de origem latinas, árabes e orientais. $O$ termo landschaft acaba sendo por onde caminharemos na discussão da paisagem:

\footnotetext{
"Landschaff' se refere a uma associação entre sítio e os seus habitantes, ou se preferirmos, de uma associação morfológica e cultural. Talvez tenha surgido de "Land schaffen", ou seja, criar a terra, produzir a terra. Esta palavra transmutada em "Landscape" chegou a geografia norte-americana pelas mãos de Sauer que, cuidadosamente, enfatizava que seu sentido continua sendo o mesmo: o de formatar (land shape) a terra, implicando numa associação das formas físicas e culturais. (HOLZER, 1999, p.152).
}

Landschaft, diferente de outros termos, os quais ficam muito presos ao sentido da visão é mais abrangente, portanto, supera a análise apenas visual, comportando um conjunto de significados e visões de mundo que fornecem ao conceito uma complexa trama de interpretações e sua funcionalidade supera em muito as demais traduções. Todavia, as outras acepções de paisagem, frequentemente aparecem mais ligadas à questão das artes, que nos leva a discussão sobre a sua abordagem neste campo, especialmente na pintura, o que é sugerido por aqueles autores que se debruçam sobre a história do conceito, situando-o, algumas vezes, na pintura renascentista. 
A pintura da paisagem tem diversas fases diferentes, mas, até recentemente, era relacionada à concepção de natureza pelo ser humano e terminava sendo vista como exposição, em diversos momentos históricos, das representações artísticas. Nesse sentido, trata-se de uma exposição da visão de mundo de um determinado grupo social. Colocada nesses termos, verificase que a paisagem se torna uma construção social, portanto, nossas indagações devem se voltar sobre as intencionalidades que nela é depositada.

Alexander Von Humboldt foi o primeiro cientista a utilizar o termo paisagem como objeto de estudo. De fato, este naturalista buscava estabelecer uma relação global entre as dinâmicas da natureza de cada lugar, denotando uma preocupação contemporânea em relação à paisagem que é a abordagem integrada de seus componentes (SANSOLO, 2007). Paul Vidal de La Blache, frequentemente considerado o fundador da escola de geografia francesa, acrescenta a discussão da fisionomia ${ }^{1}$ da paisagem, algo que Humboldt também já trabalhava, mostrando que se precisa ir além do plano das aparências e entender o processo de formação da paisagem.

Outro geógrafo importante dentro desta discussão seria Carl Troll, o qual aponta:

"a paisagem é a síntese do espaço, na paisagem que se encontra o objeto da geografia, extraído por meio da correlação entre as ciências naturais, humanas, econômico-sociais, considerando como uma unidade orgânica pertencente a uma taxonomia geográfica, em uma determinada escala" (TROLL, 1950, apud BESSE, 2006)

Troll também vê na paisagem a diferenciação entre o fisionômico e o funcional. Semelhantemente, Carl Sauer aponta a paisagem como o objeto de estudo da geografia, mas acaba limitando este rico conceito apenas ao que é evidente.

\footnotetext{
${ }^{1}$ s.f. Semblante; conjunto das características distintivas e particulares, feições e traços, do rosto humano. Aparência; a expressão própria desses traços. Figurado. Aspecto particular e próprio de alguma coisa: a fisionomia da educação está decadente. Ecologia. Fachada própria ou aspecto de uma vegetação que se relaciona com suas formas de vida e de seus componentes. (Etm. do latim: physionomia) disponível em: < http://www.dicio.com.br/fisionomia/> acesso em 10 julho 2015
} 
Sauer procura enfatiza as análises funcionais e estruturais de modo sistemático, deixando claro sua vinculação ao positivismo. A partir disso, a análise da paisagem se dá de forma rasa, limitada apenas aos sentidos, pensando apenas na aparência imediata do espaço, como uma fotografia.

Nas formulações à crítica da geografia clássica, é recorrente, a ideia de que a paisagem se constituía apenas como uma porção visível do território, colocando o espectador separado da paisagem, ocorrendo, assim, a valorização do sentido da visão e em muitos casos um relevo mais alto era considerado crucial para a análise da paisagem assim se poderia ter uma visão de maior alcance e ignorando todos outros modos de perceber e sentir a paisagem.

\footnotetext{
Estes geógrafos profissionais pioneiros associaram a "paisagem" à porções do espaço relativamente amplas, que se destacavam visualmente por possuírem características físicas e culturais suficientemente homogêneas para assumirem uma individualidade. (HOLZER, 1999, p.152)
}

Muitos autores acabam também por pensar a paisagem apenas como uma forma construída a partir das relações humanas. Para o professor, Milton Santos, por exemplo,

"Paisagem e espaço não são sinônimos. A paisagem é um conjunto de formas que, num dado momento, exprime as heranças que representam as sucessivas relações localizadas entre homem e natureza. O espaço são as formas mais a vida que as anima" (2002, p.103).

Em sua afirmação, Santos coloca a paisagem em segundo plano para valorizar o espaço e assim a paisagem é pensada apenas como uma forma e refém apenas da vontade humana e ignora diversos fatores naturais em diversas escalas temporais, em conflito com Santos podemos destacar a posição de Ab'Saber:

Em uma escala de tempo e espaço global, mesmo com as mudanças promovidas pelo homem organizado em sociedade, as formas da paisagem no planeta, a despeito de formas reconhecidamente produzidas pela ação das sociedades humanas, ainda são compostas por paisagens zonais e azonais definidas pela dinâmica natural (AB'SABER, 1978). 
Parece-nos evidente que neste debate, a paisagem está diretamente relacionada com a questão de escalas espaço-temporais onde em uma escala com maior detalhamento podem se destacar o papel do ser humano na transformação da paisagem, mas em um longo período temporal, ou de menor detalhamento a paisagem acaba por ser muito mais transformada por processos naturais. Outro ponto que em que se ressalta a polêmica das colocações do professor Milton Santos é que para ele, em alguns momentos, a paisagem fica muito restrita as formas físicas. Mais à frente veremos que a paisagem deve ser situada para além da pretendida morfologia.

Nos últimos anos diversos autores permaneceram questionando a noção clássica de paisagem, não a restringindo apenas uma parte do território, mas sim como uma forma de ver e representar o mundo, representações estas que estão carregadas de ideologia e intencionalidade, que se apresenta, invariavelmente ligada ao modelo ocidental, patriarcal, colonizador que se coloca como verdade universal. Há mesmo registros de uma tendência na qual se olha novamente para artes de uma forma mais crítica, em cuja direção se percebe como a classe dominante se utilizava das obras para reproduzirem sua ideologia.

A paisagem pode levar a interpretações diferenciadas, diversas formas de ver. Sabemos que cada homem tem sua construção histórica, política e cultural diferenciada por suas experiências e pelos lugares. A paisagem será lida de maneiras diferentes por pessoas diferentes. A paisagem também não é inocente; ela mesma carrega toda uma carga ideológica e cultural, a qual direcionará a diferentes interpretações de acordo com os filtros dos olhares humanos. Análises mais cuidadosas acabam nos levar a verificar como a construção da paisagem por ações humanas busca representar como pensa a classe dominante de determinado período histórico, como é destacado a seguir:

Sendo a paisagem o que se vê, supõe-se necessariamente a dimensão real do concreto, o que se mostra, e a representação do sujeito, que codifica a observação. A paisagem resultado desta observação é fruto de um processo cognitivo, mediado pelas representações do imaginário social, pleno de valores simbólicos. A 
paisagem apresenta-se assim de maneira dual, sendo ao mesmo tempo real e representação (CASTRO, 2002)

Avançando na discussão, a paisagem acaba por ser a maneira como o espaço é representado e ao mesmo tempo percebido, sendo constituída de diversos símbolos, que reproduzem as normas culturais estabelecendo os valores de grupos dominantes para toda uma sociedade, representando como essa classe dominante pensa o espaço e assim no lugar de esclarecer acaba por esconder, mistificar e naturalizar diversas situações. Eis aqui uma abertura para que, no estudo da paisagem, também se busque apreender as relações do poder.

\begin{abstract}
Um grupo dominante procurará impor sua própria experiência de mundo, suas próprias suposições tomadas como verdadeiras, como a objetiva e válida cultura para todas as pessoas. O poder é expresso e mantido na reprodução da cultura. Isto é melhor concretizado quando menos visível, quando as suposições culturais do grupo dominante aparecem simplesmente como senso comum. Isto é as vezes chamado de hegemonia cultural. Há, portanto, culturas dominantes e subdominantes ou alternativas, não apenas no sentido político, mas também em termos de sexo, idade e etnicidade. (COSGROVE, 1999, p.104-105).
\end{abstract}

O que nos deve inquietar, desta maneira, é como as relações capitalistas de produção acabam por criar estratégias de dominação e qual é o papel da paisagem para assim dar continuidade a sua reprodução. Nessa direção, também nos inquieta como a paisagem acaba se tornando mercadoria, levando a seu fetichismo. A paisagem é apresentada como um espetáculo, que terá a função de naturalizar certas relações e, em certo sentido, assume ares de reificação, escondendo todo o processo, pois o que se revela, na verdade é uma autonomização da forma.

Toda essa discussão nos faz chegar à conclusão de Berque (1988), para quem a paisagem é, de forma simultânea, marca e matriz. Nessa perspectiva, verifica-se a capacidade que a análise da paisagem pode gerar para pensarmos na condição da existência e da ação humanas. Se por um lado ela é vista por um olhar, pelo outro ela determina este olhar. Berque (op. cit., página, 86) ainda aponta que a paisagem é plurimodal (passiva-ativapotencial.), pois há um sujeito para o qual a paisagem existe; a paisagem e 0 
sujeito são co-integrados em um conjunto unitário que se autoproduz e se autoreproduz".

Dentre os diferentes olhares sobre a paisagem temos o olhar do geógrafo, que, do ponto de vista do método, deve ser tomada como uma impressão que contém todo um processo escrito, o conteúdo por trás da paisagem pode muito bem não ser o que a paisagem de imediato se propõe a mostrar, por isso o geógrafo deve desconfiar da paisagem, investigá-la e assim procurar entender todo o processo que está embutido nela. É o que se pretende expor, neste trabalho: apontar as contradições do processo de construção do shopping Central Park em Duque de Caxias, apontado as modificações que ocorrerão na paisagem e como o bem-estar na paisagem será modificado em detrimento dos projetos econômicos apresentando de maneira crítica todas as transformações que esse processo trará para 0 entorno e quais são os grupos envolvidos nesta disputa.

\section{Conflitos na paisagem de Duque de Caxias: explorações iniciais entre os conflitos entre o valor de uso $x$ e o valor de troca}

A inspiração da pesquisa ocorreu a partir de um momento em que estava caminhando pela Avenida Leonel Brizola em Duque de Caxias e observei a instalação de uma nova lojas de departamentos (daquelas que compõe as grandes redes do varejo e que tem filiais em grandes centros comerciais de áreas nobres e grandes shoppings centers) em uma área com uma paisagem dominada por pequenos comércios. $O$ que me incomodou foi 0 fato de já existir uma loja desse porte a poucas ruas de distância, no famoso calçadão de Duque de Caxias, como é apresentado na figura 1. 


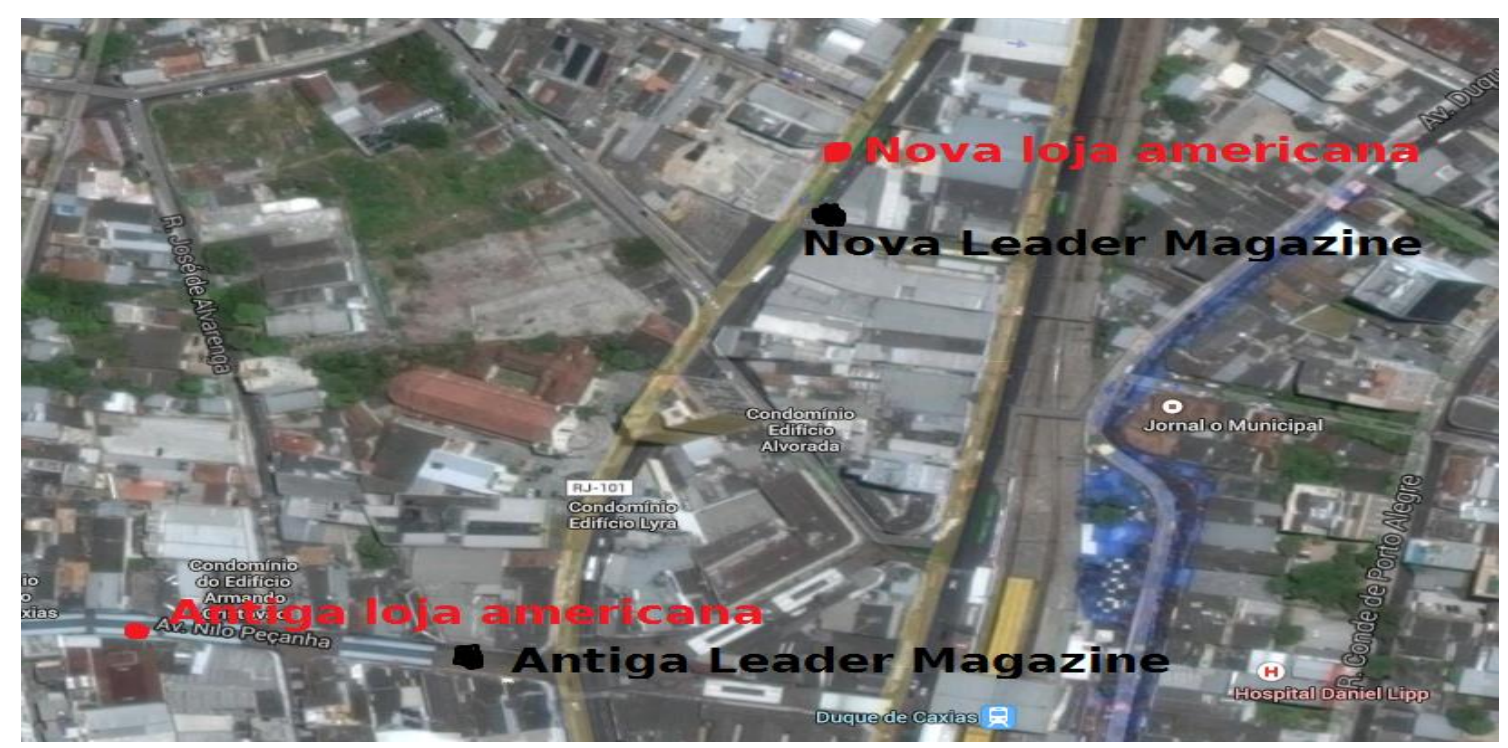

Figura 1 foto retirada do google.com.br/maps e editada pelo autor para sinalizar as lojas.

Observando o entorno consegui perceber outra loja de grande porte chamada Leader Magazine. A impressão inicial era a de que um empreendimento em uma região não prospera para o tipo de loja e pelo fato de já existir ambas as Lojas (Lojas americanas e Leader Magazine) bem próximas aos novos empreendimentos, ou seja, haveria, a priori, maior concorrência entre ambas e com o comércio varejista local. Não satisfeito fui procurar informações sobre essa mudança da paisagem nesta parte do centro de Duque de Caxias. Fui informado que estava para ser construído um grande shopping naquele lugar. Em seguida, procurei informações sobre onde seria construído o shopping descobri que existia um confronto entre a empresa $A B L$ Shopping Empreendimentos e Participações S.A. e a sociedade civil organizada através da entidade FORAS (Fórum de oposição e resistência ao shopping) e o Estado se colocando como "mediador" deste conflito, mas como já sugerido, há evidências de que o Estado não é neutro e tem tende para um lado, como veremos em seguida.

O shopping chamado de Central Park será construído em uma área de 11.718,72 $\mathrm{m}^{2}$, ao lado da Catedral de Santo Antônio e da escola municipal Doutor Álvaro Alberto, como foi apresentado na projeção feita pelo IPPUR (Instituto de Pesquisa e Planejamento Urbano e Regional) e sinalizadas à escola e catedral pelo autor na figura 2. Já de imediato se percebe o grande destaque do futuro shopping na paisagem do lugar, sendo a maior forma de 
maior dimensão da redondeza. Numa observação mais precisa, se percebe também que tanto a escola como a catedral são minimizadas pelo novo empreendimento. E aqui já se anuncia o conflito decorrente entre as representações das paisagens pretéritas, a escola pública e a instituição religiosa (muito mais vinculadas à esfera do uso), e a paisagem envolta no referido shopping (sinalizando a proeminência do valor de troca)

A construção deste shopping irá alterar muito a paisagem e a dinâmica do lugar, afetando diretamente a população e as atividades no entorno. Mas não fiquemos retidos apenas à paisagem como aparência, pois é preciso ir além disso, como é mostrado pelo historiador da paisagem John Brinckerhoff Jackson:

É assim que deveríamos considerar as paisagens: não somente em função de sua aparência ou de sua conformação a tal ou tal ideal estético, mas também de acordo com sua maneira de satisfazer as necessidades elementares como a de dividir algumas de suas experiências sensoriais numa situação familiar: canções populares, pratos populares, uma espécie particular de clima que supostamente não se encontra em nenhuma outra parte, um esporte ou jogo especial, que só se praticaria naquele lugar. Estas coisas que nos lembram do que nós somos, ou que vimos, de um lugar particular: um país, uma cidade, um bairro. Uma paisagem deveria estabelecer um laço entre as pessoas, o laço que cria a língua, as maneiras, a prática do mesmo tipo de trabalho ou de lazer, mas sobretudo uma paisagem deveria conter o tipo de organização espacial que favorecesse essas experiências e essas relações: espaços para se reunir, para celebrar, e espaços para a solidão, espaços que não mudam nunca e permanecem sempre tal como a memória os pinta para nós. São estas algumas características que dão a uma paisagem seu lado único, que lhe dão um estilo, e que fazem com que nos lembremos delas como emoção (2005, p. 42) (Tradução feita pelo autor). 


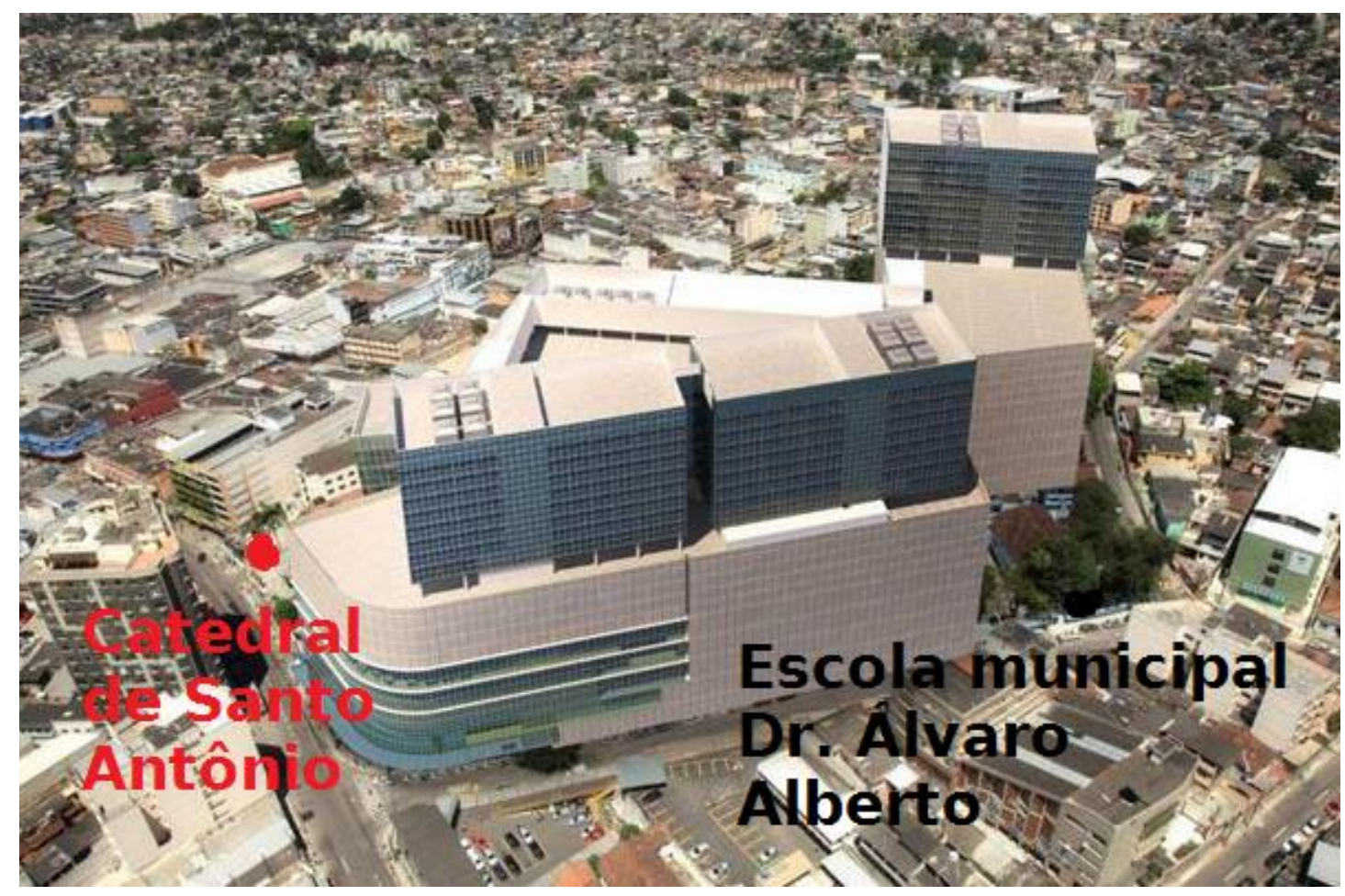

Figura 2 Retirado do Site www.ablshopping.com.br, editada pelo autor apontando a escola e a catedral.

Não podemos ficar presos apenas à forma estética da paisagem, mas sim como ela influência o espaço em uma complexidade de modos que levam a questão do bem-estar. Procuraremos apontar como este empreendimento irá afetar a relação da paisagem com a população e atividades do entorno. 0 IPPUR procurado pelo FORAS, fez um estudo do "impacto" que a construção do shopping geraria ao entorno. Dentro deste estudo muitos dos resultados apontam como o bem-estar coletivo está em cheque.

O primeiro apontamento do IPPUR foi sobre a questão de aproveitamento do solo na região. Segundo o Plano Diretor da cidade, a área de construção do shopping é considerada uma zona controlada e que tem restrições à ocupação intensiva do solo. Essas zonas controladas deveriam priorizar a reversão de processos de adensamento urbano, instalação de infraestrutura e estudar sobre a intensidade da ocupação em áreas limítrofes de paisagens notáveis. Nisso, se conclui que o empreendimento vai contra 0 Plano Diretor da cidade, pois representa uma forma ultra-intensiva de aproveitamento do solo, com área edificada equivalente a quase sete vezes a área do terreno, causando assim um agravamento do adensamento da área 
que já está saturada, reconhecida pelo referido plano; em nenhum momento foi instalada infraestrutura necessária que amenizariam as "perturbações" geradas pelo empreendimento como, por exemplo, ampliação das redes de esgoto, abastecimento de água que já é uma situação crítica em boa parte da cidade, além do sistema viário.

A área do terreno de $11.718,72 \mathrm{~m}^{2}$ permitiria a construção máxima de $28.124,93 \mathrm{~m}^{2}$ sendo o índice de 2,4 de aproveitamento do solo. A construção tem o projeto de ocupar o espaço de 71.880,69 m²; o índice de aproveitamento do solo vai para 4,34 sendo o estacionamento levando 0 índice para 7,80. Segundo ainda o Plano Diretor o índice de 2,4 não deveria ser ultrapassado nem por pagamento, isso influenciará diretamente no trânsito; a empresa $A B L$, contratou duas empresas para fazer um estudo de "impacto" resultante da construção do shopping. Em contrapartida, o IPPUR questionou os resultados obtidos pelas empresas de consultoria conhecidas como CCY - Consultoria de Engenharia LTDA e a empresa M2a.

A empresa CCY fez o estudo em outubro de 2012, e se utilizou de três modelos diferentes, o primeiro questionamento do IPPUR foi sobre o modelo escolhido na apresentação dos resultados do estudo, que é o modelo CET-SP, que foi um modelo criado para construção de shoppings na capital paulista. $O$ Instituto considerou um erro grave, pois o espaço da capital paulista se diferencia e muito da cidade de Duque de Caxias. Entre os três modelos o CET-SP foi o de menor resultado na quantidade de carros que irão circular nas ruas pós-construção do shopping que seria de 4.447 carros as sextas feiras e 7.502 aos sábados. O correto seria, conforme observações do IPPUR-UFRJ, fazer uma média dos três modelos para assim chegar a um resultado de mais precaução. A empresa ainda não computou na pesquisa as torres comerciais e o apart hotel que será construído no mesmo espaço do shopping. Muitas ruas ao entorno do shopping são de caráter residencial, com três escolas na proximidade, com ruas de $3,5 \mathrm{~m}$ que acabam por gerar um trânsito mais lento. A empresa $\mathrm{M} 2 \mathrm{a}$ chegou a resultados divergentes em alguns pontos, mas não demostrou como chegou ao resultado que é considerado algo que pode levar a desconsideração da pesquisa; os estudos do IPPUR-UFRJ concluíram que os 
fluxos de carros as sextas feiras seriam de 6.895 cerca de $35 \%$ maior do que da empresa CCY, o que resultaria no aumento para 67 minutos o tempo de engarrafamento da região no horário de pico das ruas no entorno do shopping, impactando significativamente sobre o bem-estar que a paisagem geraria para a população que por ali transita, uma paisagem que está sendo preparada para que a troca seja muito mais importante que o uso.

Cabe expor o papel do Estado e apontar que ele não é neutro e está justamente sintonizado com a lógica da acumulação capitalista, tanto que a emissão da licença para construção do shopping foi liberada antes de ser feito o EIV (estudo de impacto na vizinhança). O RIV (Relatório de impacto na vizinhança) nem se quer foi feito, desrespeitando as leis, e mais, o próprio Estado restringe o acesso a totalidade do processo, o qual já foi solicitado diversas vezes.

Outro grande exemplo foi que a outorga onerosa, um imposto recolhido após a licença de construção ser autorizada, foi recolhido dois meses antes, o que nos passa a impressão que o fato já está consumado em função do empreendedor.

Outra questão de extrema importância que afeta diretamente a paisagem do lugar em várias proporções é a questão ambiental. O espaço em que o shopping Central Park irá ser construído era a última mancha verde no centro de Duque de Caxias, um bosque que dividia o espaço com a escola municipal Doutor Álvaro Alberto. Nota-se aí uma grande contradição incoerência, por assim dizer, desmatar toda uma área verde e o no mesmo lugar colocar um shopping chamado de Central Park que se referencia numa área verde. $\mathrm{O}$ bosque contava com 167 árvores centenárias sendo 48 delas vegetação de mata atlântica. Ocorreu o corte de todas as árvores do espaço como pode ser observada nas figuras 3 e 4, e, a autorização da prefeitura ocorreu antes mesmo da licença ambiental ser emitida

O Estatuto da Cidade, em seu artigo $2^{\text {a }}$, inciso XIII expressa que se faz necessária audiência pública para empreendimentos com efeitos potenciais negativos para a população, algo que não ocorreu, mais uma vez a posição do Estado se revela em favor de interesses do capital financeiro. 


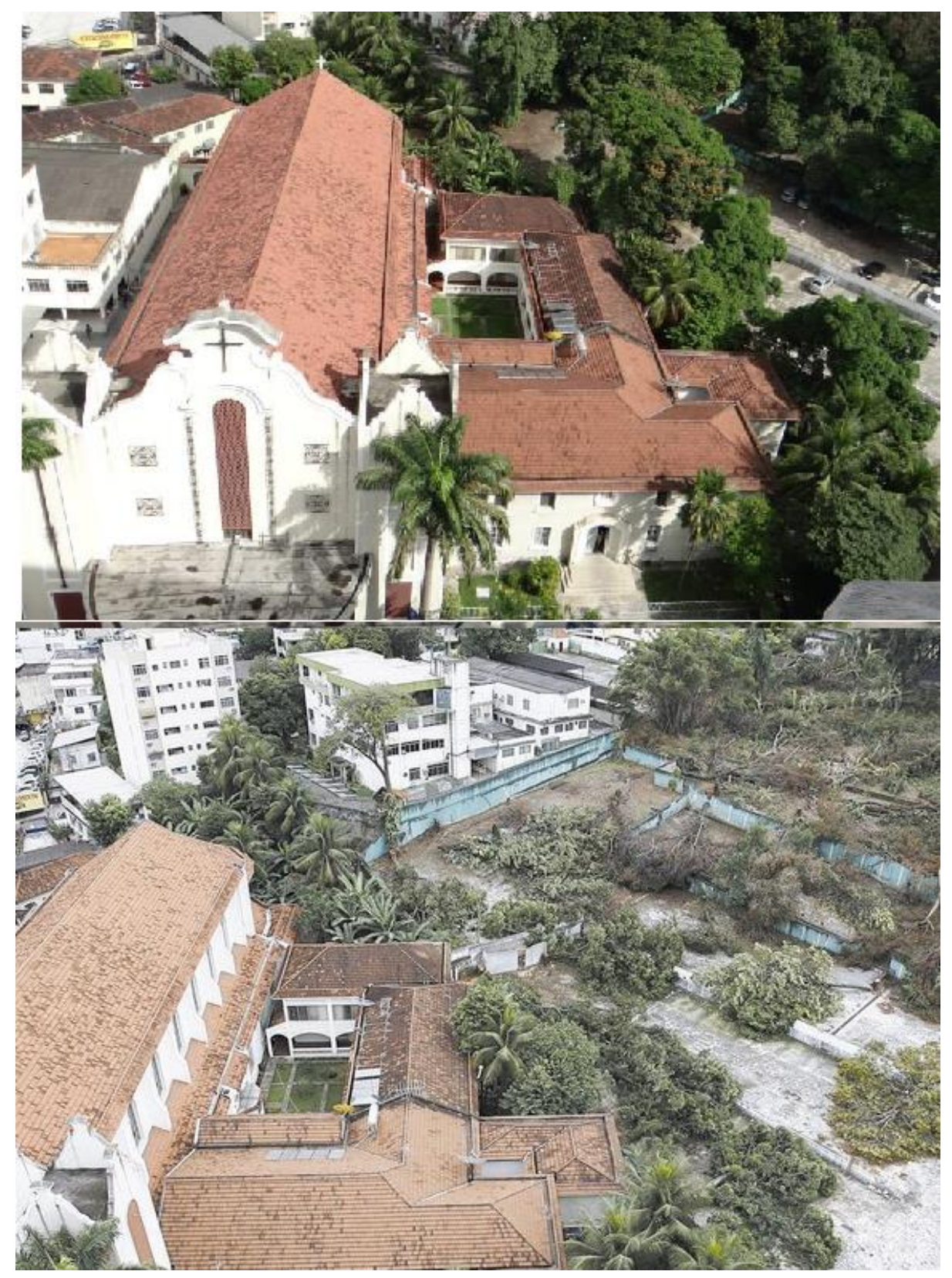

Figuras 3 e 4 imagens retirada do site foras.com.br que apresenta o corte das árvores.

A obra, segundo, o IPPUR pela sua magnitude tende a gerar "impacto" ambiental significativo, sobretudo, na dispersão atmosférica, concentrando poluentes modificando o microclima gerando o que conhecemos como "ilha de calor". Segundo o ambientalista Sebastião Raulino, mestre em Ciência Ambiental pela Universidade Federal Fluminense e doutor em Planejamento Urbano pela Universidade Federal do Rio de Janeiro, em uma entrevista ao site do FORAS sobre as transformações feitas na paisagem da área, aponta: "Ambiente sem árvores diminui o bem-estar, porque a tendência é aumentar 
temperatura e concentração de poluentes", lembra-nos ainda que a cidade já apresenta bolsões de calor, por conta da impermeabilização do solo". Para o pastor da Igreja Maranata, Davi Silveira (que reside nas proximidades), após o corte das árvores, já é possível sentir o aumento do calor e a incidência de mosquitos. Nesse sentido, é válido apontar: já no início do processo de transformação da paisagem, as diferenças já estão sendo sentidas pela população do lugar.

A parede lateral do shopping ocupará quase todo o quarteirão. O problema é que a mesma será uma fachada que não tem relação com o entorno imediato. No caso do shopping essa relação se daria por vitrines, será um grande paredão, o que, segundo o IPPUR, gera a redução da percepção de segurança na paisagem ao longo da via, denunciando que o empreendimento nem sequer consegue valorizar a vida comunitária no próprio perímetro.

A instalação da edificação de altíssima intensidade de uso do solo precisamente ao lado da catedral de Santo Antônio, uma edificação considerada com um grande valor histórico, cultural, religioso e afetivo na paisagem do município será "escondida" e "diminuída". A escola municipal já vem sentindo as "perturbações" com o início do projeto, pois o corte das árvores afetou a estrutura física da escola podendo se agravar mais ainda com o início das obras, outras "perturbações" que serão sentidas com o fim da construção. Além da tendência de precarização da visibilidade e da circulação atmosférica, também podem ser apontadas a preservação, iluminação e ventilação do lugar. Tanto a Catedral como a escola estão em processo de tombamento pela sua importância para o município. No caso da Escola Doutor Álvaro Alberto (antiga escola regional de Merity), é considerada um patrimônio da educação em Caxias, um dos motivos é que a mesma foi a primeira escola do Brasil a servir merenda para os alunos e que fez a escola levar o apelido de "Mate com Angu".

Segundo o Plano Diretor da cidade, bens de valor cultural necessitam de proteção a sua visibilidade, permitindo que a população tenha acesso ao bem e assim à sua própria cultura e história. O Plano Diretor também considera bens de interesse cultural aqueles que tombados ou não apresentem, 
justificadamente, valores de interesse do patrimônio cultural, o que já inviabilizaria todo o projeto de construção do shopping, essa nova paisagem, no fundo, reflete a disputa entre o valor de uso e o valor de troca.

\section{Sociedade civil organizada}

Como já citado no presente trabalho, enfatizarei aqui o objetivo do FORAS (Fórum de Oposição e Resistência ao Shopping) como um movimento de resistência que luta contra o shopping que será construído no centro de Duque de Caxias, que, possivelmente ocasionará graves "impactos" urbanísticos, sociais, ambientais e de vizinhança. A partir disso, esse grupo de ativistas tem por método ações contra a criação desse grande empreendimento, que advém de uma ordem distante que acarretará uma alteração na paisagem que refletirá a valorização do solo no seu entorno e por sua vez o encarecimento do mesmo, mudanças no micro-clima e alterações no trânsito gerando um desconforto para a população do entorno.

O FORAS nasce da união de várias entidades da sociedade civil, que tem por objetivo a preservação da área a qual foi planejada para execução desse grande empreendimento, que é o Shopping. A preservação da natureza e do meio ambiente são pautados pelo FORAS, pois a presente área era a última área verde do centro de Duque de Caxias, que já é praticamente todo urbanizado e que tinha por exceção esse lugar, o qual tem por história as raízes indígenas, quilombolas, sambaqui, etc. Tudo isso está sendo apagado por medidas vinda dos empreendedores e tendo como aliada a prefeitura de Duque de Caxias. A Secretaria de Meio Ambiente autorizou o corte de 167 árvores, mesmo com as várias tentativas da sociedade de impedir, pois serão os que por sua vez serão afetados com a construção desse Shopping.

As instituições que compõem o FORAS são de diversas frentes de lutas e que tem suas particularidades, mas que se uniram e universalizaram suas lutas, indo contra a construção do shopping. Essa instituição tem promovido ações políticas para a "derrubada" desse grande empreendimento, cujo objetivo é, ao que tudo indica, beneficiar os grandes empresários, os quais iram lucrar com o mesmo, diferente da população que em sua maioria fica presa ao 
senso comum de análise da paisagem e aceita como discurso único o fato desse empreendimento ser um grande gerador de empregos. Porém essas instituições sabem bem que vai muito além disso, pois essa construção não preserva o meio ambiente, causará transtornos sociais, urbanos e de mobilidade na área central da cidade, prevalecendo a troca em detrimento do uso, a importância dessa luta é reforçada por Besse:

\begin{abstract}
A paisagem não pode ser considerada apenas um objeto ou um campo de exercício artístico: ela contém também desafios sociais, culturais e econômicos, até mesmo políticos e, sem dúvida também, de agora em diante, ambientais e sanitários, desafios que devem ser levados a sério e que, sem considerá-los, a noção de bem-estar não tem muito sentido. $(2014$, p. $(244,245)$.
\end{abstract}

Uma de suas pautas também é a preservação da Escola Municipal Dr. Álvaro Alberto, que também conhecida na cidade pelo seu apelido, "Mate com Angu". A escola tem um notório histórico na cidade, sendo ela uma das primeiras escolas da região, a primeira a ter a ideia de servir merenda aos alunos, que inovara na forma de ensinar, prestara assistência às famílias e por sua vez marca certa influência sobre o desenvolvimento da cidade. Essas práticas e, provavelmente algumas outras, demonstra-nos como a Escola Municipal Dr. Álvaro Alberto se tornou referência na história da educação do Brasil, sendo conhecida nacionalmente e fora do país. Existe um movimento composto por moradores da cidade, estudantes e professores que há quase dez anos luta pela preservação da escola, que é um patrimônio como outros existentes na cidade.

Entretanto, a escola está no entorno do local que será construído o shopping, a qual poderá ser ameaçada por essa construção. Mediante esse fator várias instituições pertencentes ao FORAS se uniram para a retomada de mobilizações que tem por objetivo o tombamento da escola. Medidas foram tomadas para a preservação da escola e entre elas, foi entregue à Secretaria Municipal de Cultura e Turismo o requerimento com dezenas de assinaturas, solicitando o Tombamento da Escola Dr. Álvaro Alberto pela prefeitura, isto é, demanda-se um Decreto municipal garantindo a proteção e preservação da escola o qual pela lei municipal teria 105 dias para ser concluído e 
encaminhado ao prefeito para decretar o tombamento definitivo, porém isso ainda não aconteceu.

O que se pode perceber são as intencionalidades por trás do descaso das autoridades de Duque de Caxias, pois toda Lei de Tombamento, acaba estendendo a proteção do entorno em volta do bem a ser tombado. Logo a área não pode sofrer intervenções sem estudos e autorização das autoridades competentes. Cabe acrescentar ainda que a Lei Municipal, no 2300/2009, de Duque de Caxias garante a proteção de um entorno a serem estipulados entre 50 e 500 metros. Diante dessa questão, os representantes do poder público, tiveram como proposta, votada e ganhada no Conselho Municipal de Cultura, que só se daria continuidade ao processo de tombamento somente após modificar a lei municipal de tombamento, retirando o artigo que garante uma área de proteção no entorno da escola. O que nos deixa como questões: a quem o Estado serve? Para quem as leis são feitas? Até o momento, essa investigação parece apontar que os mandatários do poder se mantém aliado aos detentores do capital. Percebe-se também como a paisagem deve ser tomada para além da sua morfologia, conforme já sinalizado acima.

Podemos salientar ainda que, a partir das atitudes tomadas pelas autoridades de Duque de Caxias, que não é com o cidadão caxiense que os mesmos estão preocupados, e sim com os grandes empresários os quais irão gerar lucros e investimentos que serão destinados para os cofres públicos. Porém, aumento das receitas não significa melhorias sobre as condições de vida da população.

Muitas lutas já foram incorporadas pelo FORAS e continuam sendo acrescidas outras iniciativas. Entre elas estão as panfletagens feitas na cidade, audiências públicas, participação em programas de rádio, lutas jurídicas, estudos dos impactos e a mobilização da comunidade, algumas intervenções na paisagem ficaram registradas na área como podem ser vistas na figura 5. 


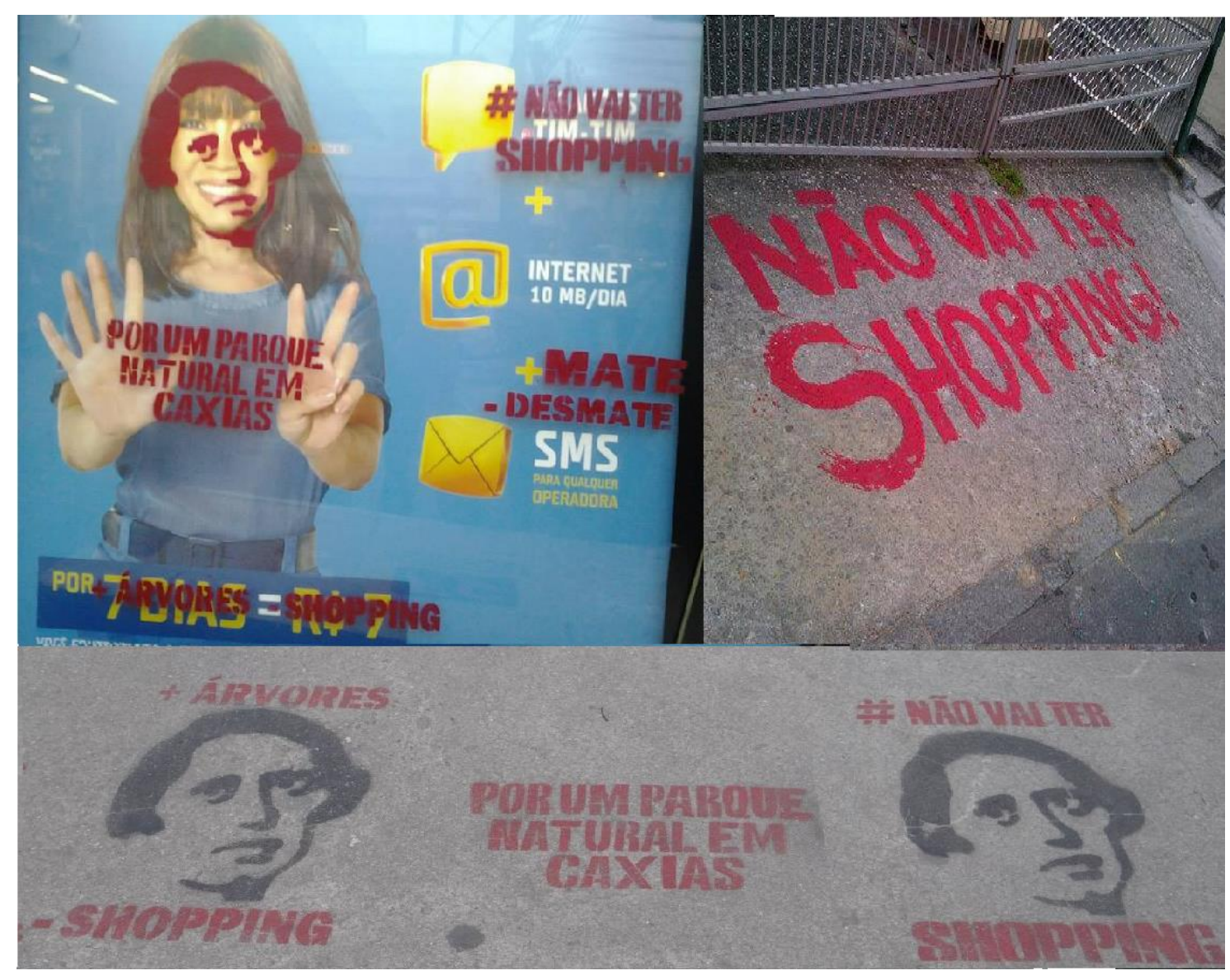

Figura 5 imagens retiradas do site foras.com.br

Notamos, assim, que a paisagem ainda está em disputa e é a partir de forte mobilização política, que a construção do shopping poderá ser impedida, pois se não fossem essas medidas, tomadas pelo FORAS, contra esse projeto que atinge ao morador, ao cidadão de Duque de Caxias e que serve aos grandes empresários, o andamento da construção desse shopping já teria sido iniciado.

\section{Considerações finais}

Percebemos, pelo exposto, que a paisagem vai muito além do que se apresenta aos nossos olhos. Entre a paisagem que nos é apresentada e aquilo que de fato ela representa existe todo um processo que mascara toda a complexidade e naturaliza determinadas situações. Existem forças, nem sempre evidentes, muitas delas impostas pela ideologia dominante que nos fazem acreditar naquilo que vemos sem questionar a engrenagem de sua 
construção enquanto tal. O geógrafo tem por obrigação desconfiar da paisagem, pois, ler a paisagem vai muito além de percebermos sua aparência. Ler a paisagem então é no mínimo compreendê-la como fazendo parte de um contexto histórico-geográfico, social, político, territorial, cultural, estético e ético, além dos interesses ideológicos postos em jogo nessa "ciranda" sugerida por certa produção social do espaço. É preciso desconfiar e investigar a paisagem com uma análise crítica levando em consideração toda complexidade que envolve a formação da mesma.

Retornando ao momento inicial da pesquisa, as novas lojas que se instalaram na região de construção do novo shopping Central Park, são novas "marcas" na paisagem, marcas essas que são "matrizes" de um grande processo de gentrificação ${ }^{2}$ mista (negócios e pessoas) onde as modificações feitas que favoreçam a troca em detrimento do uso na área, o próprio ato de destruir um bosque para colocar um shopping no lugar põe em evidência 0 conflito entre o uso e a troca. A gentrificação já é vista na paisagem com essas novas lojas de grande porte e a saída dos pequenos comerciantes cuja algumas lojas já serão demolidas para as obras. A situação se torna mais crítica quando se percebe, conforme amplamente divulgado nas reuniões do FORAS, que nenhum dos comerciantes (do comércio de pequeno porte) foi indenizado, devido ao ato de as lojas serem alugadas.

Por fim pode se considerar que a "nova" configuração da paisagem do Centro de Caxias, se for consolidada, irá mudar muito como a paisagem é sentida (e praticada). Podemos considerar dois principais olhares dessa nova paisagem: a dos empresários que conseguirão através das novas dinâmicas aumentar sua arrecadação a partir dessas intervenções; em contrapartida

\footnotetext{
${ }^{2}$ A palavra gentrificação (do inglês gentrification) pode ser entendida como o processo de mudança imobiliária, nos perfis residenciais e padrões culturais, seja de um bairro, região ou cidade. Esse processo envolve necessariamente a troca de um grupo por outro com maior poder aquisitivo em um determinado espaço e que passa a ser visto como mais qualificado que o outro. O termo é derivado de um neologismo criado pela socióloga britânica Ruth Glass em 1963, em um artigo onde ela falava sobre as mudanças urbanas em Londres (Inglaterra). Ela se referia ao "aburguesamento" do centro da cidade, usando o termo irônico "gentry", que pode ser traduzido como "bem-nascido", como consequência da ocupação de bairros operários pela classe média e alta londrina. Disponível em: < http://vestibular.uol.com.br/resumo-dasdisciplinas/atualidades/gentrificacao-o-que-e-e-de-que-maneira-altera-os-espacosurbanos.htm > 10 julho 2015.
} 
temos a população do entorno que já vem perdendo a qualidade do seu bemestar durante o processo. Há indicadores também de que a sociedade civil organizada está demonstrando não ficar presa ao "discurso do fim da história", de que não há como vencer e que tudo já está dado. A luta organizada está avançando, mais de vinte entidades estão organizadas lutando pela disputa desta "paisagem".

\section{Referências}

AB'SÁBER, Aziz. Potencialidades Paisagísticas do Brasil. São Paulo, Instituto de geociências, 1978.

BERQUE, Augustin. Paisagem-marca, paisagem-matriz: elementos da problemática para uma Geografia Cultural. Tradução de Ednês M. Vasconcelows Ferreira e Anne-Maria Milon Oliveira In: CORRÊA, Roberto L.; ROSENDAHL, Zeny (Orgs). Paisagem, tempo e cultura. Rio de Janeiro (RJ): UERJ, 1998. P. 84-91.

BESSE, J -M. Entre a geografia e a ética: a paisagem e a questão do bemestar. Trad. Eliane Kuvasney e Mônica Balestrin Nunes. GEOUSP - Espaço e Tempo (Online) São Paulo v. 18 n. 2 p. 241-252, 2014.

BESSE, J -M. O gosto do mundo: exercícios da paisagem, Rio de Janeiro (RJ). Ed. UERJ, 2014.

BESSE, Jean-Marc. A fisionomia da paisagem, de Alexander Von Humboldt a Paul Vital de La Blache. In: __ Ver a Terra, seis ensaios sobre a paisagem e a Geografia. São Paulo: Perspectiva, 2006.

CASTRO, Iná Elias de. Paisagem e turismo. De estética, nostalgia e política. In: YÁZIGI, Eduardo (org.). Paisagem e Turismo. São Paulo: Contexto, 2002. 226p. p.121-140 (Coleção Turismo)

COSGROVE, Denis. A geografia está em toda parte: Cultura e simbolismo nas paisagens humanas. In: CORRÊA, Roberto Lobato \& ROZENDAHL, Zeny 
(orgs.). Paisagem, Tempo e Cultura. Rio de Janeiro: Eduerj, 1998.123p. p.92123

HOLZER, Werther. Paisagem Imaginário e Identidade: alternativas para 0 estudo geográfico. In: ROSENDAHL, Zeny \& CORRÊA, Roberto Lobato (orgs). Manifestações da Cultura no Espaço. Rio de Janeiro: Eduerj, 1999. 248p. p.149-168 (Série Geografia Cultural)

JACKSON, J. B. De la nécessité des ruines et autres sujets. Paris : Éditions Du Linteau, 2005..

SANTOS, Milton. A natureza do espaço: técnica e tempo - razão e emoção. São Paulo: Edusp, 2002. 384p.

SOUZA, Marcelo L. de. Paisagem. In: Os conceitos fundamentais da pesquisa sócio-espacial. Rio de Janeiro (RJ): Bertrand Brasil, 2013. P. 4362

SANSOLO, D.G. Significados da paisagem como categoria de Análise geográfica. Niterói: Anpege, 2007. 